\title{
Saúde da população LGBT: uma análise dos agentes, dos objetos de interesse e das disputas de um espaço de produção científica emergente
}

\author{
I ${ }^{1}$ Erik Asley Ferreira Abade, ${ }^{2}$ Sônia Cristina Lima Chaves, \\ ${ }^{3}$ Gisella Cristina de Oliveira Silva I
}

Resumo: Revisão sistemática da produção científica sobre a saúde de lésbicas, gays, bissexuais, travestis e transexuais (LGBT) na América Latina de 2001 a 2018. Foram analisados 161 artigos, indexados nas bases de SciELO, LILACS, Pubmed e Web of Science. A análise apoiou-se nos conceitos de campo, agentes e capitais de Pierre Bourdieu e revelou que há um espaço emergente de produção sobre a temática, ocupado principalmente por agentes da Saúde Coletiva, Psicologia, Enfermagem e Psiquiatria. Nesse espaço, a questão da violência e discriminação e seus efeitos na saúde mental, no ensino e na atuação profissional tem sido principal objeto de interesse, ao lado das repercussóes de modificaçóes corporais para travestis e transexuais. Destaca-se que os subgrupos, lésbicas, gays, bissexuais, travestis e transexuais são alvos de diferentes objetos de pesquisas, permanecendo a disputa central da categorização pela ciência de cada um desses grupos.

> Palavras-chave: LGBT; homossexualidade; bissexualidade; pessoas transgênero; saúde.

\author{
${ }^{1}$ Instituto de Saúde Coletiva, \\ Universidade Federal da Bahia. \\ Salvador-BA, Brasil (erikasley@ \\ hotmail.com). \\ ORCID: 0000-0001-5780-1229 \\ ${ }^{2}$ Instituto de Saúde Coletiva, \\ Universidade Federal da Bahia. \\ Salvador-BA, Brasil (sclchaves@ \\ gmail.com). \\ ORCID: 0000-0002-1476-8649 \\ ${ }^{3}$ Instituto de Saúde Coletiva, \\ Universidade Federal da Bahia. \\ Salvador-BA, Brasil (gisellacris@ \\ yahoo.com.br). \\ ORCID: 0000-0001-7614-6485
}

Recebido em: 06/02/2019 Aprovado em: 19/02/2020 Revisado em: 15/10/2020 


\section{Introdução}

A produção científica que toma como objeto central as questôes relativas à saúde de pessoas lésbicas, gays, bissexuais, travestis e transexuais (LGBT), com exceção de vasta produçấo sobre a epidemia de HIV/Aids, é recente e vem despertando cada vez mais o interesse de pesquisadores. No cenário internacional, já se observa um amplo conjunto de revisóes de literatura com foco nesse grupo, nas questôes de saúde mental (MARSHAL, 2011), envelhecimento (FREDRIKSEN-GOLDSEN; MURACO, 2010), uso de drogas (BLOSNICH; LEE; HORN, 2013), prevalência do câncer (HENDERSON, 2009), acesso aos serviços de saúde (ALBUQUERQUE et al., 2016), saúde sexual e reprodutiva (VET; WIT; DAS, 2017; ROBINSON et al., 2017) e problemas decorrentes da violência e discriminação (MORRISON et al., 2017).

$\mathrm{Na}$ literatura nacional e latino-americana, há número reduzido de revisôes, que têm se debruçado sobre problemas de saúde específicos dessa população, como saúde mental (TOMICIC et al., 2016) e necessidades gerais de saúde (CUNHA; GOMES, 2015; PRADO; SOUSA, 2017). Observa-se que são poucos os estudos que analisam o conjunto de produçóes sobre a temática a fim de apresentar um quadro geral das contribuições científicas até então produzidas. $\mathrm{O}$ único trabalho mais amplo encontrado deteve-se ao estudo das categorias travestis e transexuais na área da Saúde Coletiva (RAIMONDI; PAULINO; TEIXEIRA, 2016).

Pesquisas que analisaram a produção científica sobre a população LGBT podem ser encontradas em áreas externas à saúde, e demonstram mudanças importantes nos últimos anos. Maher et al. (2009), por exemplo, ao investigarem as pesquisas empíricas publicadas em língua inglesa sobre esse grupo, destacaram a existência de três fases: a dos estudos de homossexualidade como doença até 1972; a fase dos estudos da homofobia e suas consequências individuais; e a partir dos anos 1990, um enfoque sobre instituiçóes escolares, de saúde e militares.

Bento (2017), ao avaliar a produção em sociologia sobre transexualidade, argumenta pelo surgimento de um conjunto de estudos transviados que questiona os elementos do saber biomédico nas últimas décadas, constituindo uma interpretaçáo pela via da cultura e dos direitos humanos. Simóes e Carrara (2014), que examinaram os estudos socioantropológicos, afirmam que a emergência do debate sobre os direitos da diversidade sexual de gênero nesse espaço se deu a partir dos anos 2000 . 
$\mathrm{Na}$ área da saúde, é possível constatar que o interesse sobre a população LGBT localiza-se em pelo menos três áreas temáticas: as pesquisas sobre HIV/ Aids, as pesquisas sobre gênero e saúde, e aquelas sobre sexualidade e saúde. As investigaçôes sobre HIV/Aids foram as primeiras publicaçóes a destacarem as relações entre orientação sexual e saúde (SILVA; NARDI, 2011), e são as únicas com dados sistemáticos sobre essa população (GOMES et al., 2018). Contudo, elas não localizam esse grupo como seu objeto principal de estudo; seu interesse é a resposta à própria epidemia (BARROS; VIEIRA-SILVA, 2016).

Nos estudos de gênero e saúde, tanto nas pesquisas iniciais que investigavam a mulher, como nos estudos seguintes de gênero, que destacavam as relaçôes de poder e as assimetrias sociais e de saúde entre homens e mulheres (AQUINO, 2006; AQUINO et al., 2003; VILLELA; MONTEIRO; VARGAS, 2009), a categoria identidade de gênero, com a inclusão de mulheres transexuais e das travestis, e até mesmo as especificidades das mulheres lésbicas, estão praticamente ausentes enquanto tema de investigação. Já nos estudos de sexualidade e saúde, se por um lado há maior presença da população LGBT, ainda há um domínio dos temas relacionados às sexualidades heterossexuais, demonstrando um padrão heteronormativo de produção, que exclui as demandas dos grupos e pessoas LGBT, restritos nesse espaço, mais uma vez, ao HIV/Aids (FACCHINI; DANILIAUSKAS; PILON, 2013; GIAMI, 2015).

Nesse sentido, as análises sobre o espaço HIV/Aids, como também, sobre os estudos de gênero e saúde, e sexualidade e saúde, demonstram não dar conta da crescente produção sobre a saúde LGBT, o que sugere a constituição de um novo espaço de produção científica com seu interesse específico centrado nessa temática. Assim, este estudo buscou compreender a produção científica latino-americana sobre a saúde da população LGBT, os objetos em disputa, os agentes e as relaçôes de aproximação e distanciamento com os demais espaços de produção acadêmica na área da saúde, interessados pelas questóes de gênero, sexualidade e HIV/Aids.

\section{Metodologia}

Esta é uma revisão sistemática da produção científica latino-americana com foco na saúde da população LGBT. Foram incluídos artigos publicados até o ano de 2018; de pesquisas realizadas na América Latina; disponíveis na íntegra; com versóes em português, inglês ou espanhol; e de qualquer natureza, pesquisas originais, artigos de revisão, ensaios teóricos e estudos de caso. 
$\mathrm{O}$ artigo foi escolhido como fonte de dados, tanto porque sintetiza as principias informaçóes presentes em relatórios de pesquisa, teses e dissertaçóes, como por ser o produto típico do campo científico atual, com validade reconhecida por pares e dotando seus autores de capital científico. As demais publicaçôes oriundas de outros campos, como relatórios profissionais e de gestão, cartilhas, consensos de categorias, guias de conduta foram excluídos.

A escolha das bases de dados foi orientada pela abrangência a países latinoamericanos; disponíveis no portal de periódicos da CAPES, o que garantia acesso aos artigos e qualidade científica reconhecida; e que indexassem revistas da área da saúde. Assim, foram selecionadas a Literatura Latino-Americana e do Caribe em Ciências da Saúde - LILACS, a Scientific Electronic Library Online - SciELO, a Web of Science, e a PubMed.

Como estratégia de busca, foram utilizados descritores e filtros. Os descritores relacionaram-se a dimensão do grupo social (LGBT) e a dimensão da saúde, ainda foram selecionados descritores de controle para a exclusão dos artigos que tratavam da infecção pelo HIV/Aids. Após um conjunto de tentativas aplicando nas bases de dados os descritores presentes no DECS (Descritores em Ciências da Saúde) e no MesH (Medical Subject Headings), foi construído o seguinte string de busca: ("LGBT" or "gay" or "lesbian" or "transgender persons" or "homosexuality" or "bisexuality" or "sexual and gender minorities" or "gender identity" or "transsexualism") AND ("health" or "health policy" or "health services") AND NOT ("HIV" or "AIDS").

A seleção dos artigos ocorreu entre junho de 2018 e março de 2019. Em todas as bases utilizou-se a busca automática com o mesmo string de busca, sendo que cada conjunto de descritores ocupou um campo, modificando apenas os filtros entre as bases. No SciELO utilizaram-se ano e tipo de publicação; já na Web of Sicence e PubMed, ano, tipo de publicação e país de publicação. Na LILACS não houve uso de filtro. No campo principal empregou-se a categoria tópico, em todas as bases, para ampliar a seleção de artigos. A figura 1 descreve o processo de busca.

A extração e classificação de dados foram realizadas por dois pesquisadores (E.A.F.A. e G.C.O.S.), a partir da leitura direcionada e aprofundada dos textos completos dos artigos. Ainda foi realizada coleta de dados nos currículos lattes dos autores e nas páginas virtuais de instituiçóes, grupos de pesquisa e revistas.

Para a coleta do Qualis das revistas, utilizou-se a classificação do quadriênio 2013-2016 disponível na Plataforma Sucupira, a aferição do Qualis tomou como 
referência a área de vinculação de cada periódico. Para a coleta do fator de impacto, recorreu-se aos dados de 2016 da base Journal Citation Reports, acessada através do portal de periódicos da CAPES. Para a classificação das áreas temáticas foi utilizada a tipologia indicada pela Web of Science.

Quanto à análise, utilizaram-se técnicas quantitativas, como a estatística descritiva, e o referencial teórico de Pierre Bourdieu sobre o campo científico. Para este autor, o conceito de campo diz respeito a um universo social diferenciado, formado por agentes que compartilham um interesse específico. Trata-se de um espaço relativamente autônomo, mas que sofre influência do espaço social global com seus demais campos (BOURDIEU, 2004; 2011; 2008).

Cada campo tem um tipo de capital específico em disputa. No campo científico, o capital em disputa é o próprio capital científico, uma espécie de capital simbólico fundado nos atos de conhecimento e reconhecimento, que garante ao seu possuidor ganhos na ordem dos bens simbólicos, especialmente de prestígio e autoridade, e não necessariamente ganhos econômicos (BOURDIEU, 2004).

A luta no campo científico destina-se a impor princípios de visão e de divisão do mundo social a partir da verificação do real por métodos comuns de validação de teses e hipóteses. Se por um lado, os agentes mantêm um interesse comum pelo trabalho de objetivação, há concorrências tanto sobre as representaçôes formuladas dos objetos, como pelos métodos mais adequados de prova ou refutação. As lutas internas de concorrência visam à universalização de seu ponto de vista, seja dos objetos que estudam ou da própria prática científica (BOURDIEU, 2004).

Nesse sentido, na análise buscou-se conhecer os pontos de vistas, considerando que estes representam o conjunto de questóes que importam aos agentes do campo científico em determinado momento (BOURDIEU, 2004), presentes nas publicaçóes e as relaçôes que se estabelecem entre eles, as principais questôes em disputa, e as posiçôes dos agentes científicos. Foram utilizadas as seguintes variáveis:

- Agentes individuais e coletivos do campo científico: aferido a partir das características das instituiçóes e grupos de pesquisa, dos autores, e das áreas de publicação.

- Ponto de vista dos agentes: aferido a partir do tema interesse, os métodos utilizados, e nomeação dos grupos estudados.

- Capital científico dos agentes: aferido a partir da titulação e filiação dos agentes.

- Reconhecimento dos pares: tipo e prestígio da revista, Qualis e fator de impacto. 
- Características das pesquisas: tipo de estudo, técnicas e métodos utilizados.

- Características gerais do campo científico: ano e local de publicação.

\section{Resultados e Discussão}

Foram encontrados 1.128 estudos, dos quais 161 atenderam aos critérios de inclusão, número que demostra que já existe um conjunto de pesquisadores interessados na saúde da população LGBT para além da infecção pelo HIV. É oportuno observar as características dos artigos excluídos, que já revelam uma diferenciação dos estudos convencionais de gênero/saúde e sexualidades/saúde marcados pela abordagem exclusivamente cisheteronormativa das produçôes (figura 1).

Figura 1. Fluxograma de seleçấo de artigos

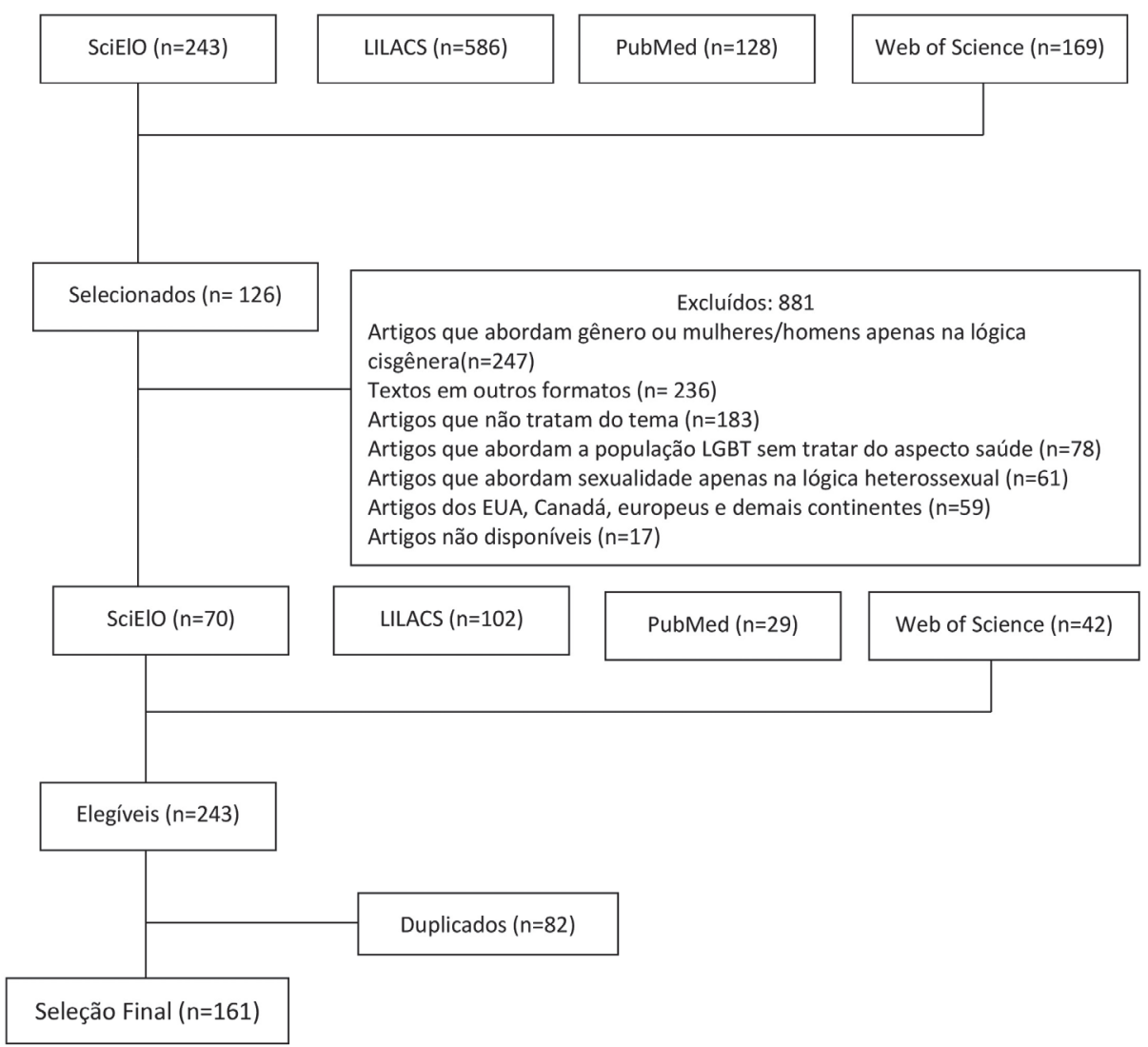

Fonte: os autores, a partir da revisão sistemática nas bases selecionadas. 
Dos estudos excluídos, 247 artigos utilizavam a categoria gênero ora como sinônimo de mulher exclusivamente cisgênera, ora como uma relação de poder, mas ainda considerando a cisgeneridade como norma única de construção de gênero. O que significa a exclusão de pessoas trans (transexuais, travestis, transgêneros), fato presente inclusive nos estudos sobre masculinidades ou feminilidades não hegemônicas.

Entre os estudos de sexualidade e saúde, 61 foram excluídos também por sua abordagem unicamente heterossexual, aqui estão as pesquisas sobre gravidez na adolescência, iniciação sexual de homens e mulheres cisgêneros, infecçôes sexualmente transmissíveis e práticas sexuais heteronormativas, portanto, também ficaram fora da seleção deste trabalho.

\section{Caraterísticas gerais da produção científica sobre a saúde LGBT}

O Brasil é o país dominante na publicação de trabalhos, isoladamente publica mais do que todos os outros países juntos. México, Chile e Colômbia também se destacam no continente, que junto com o Brasil, somam 92,6\% das pesquisas. Além disso, a maior produção foi a partir de 2014 ( $\mathrm{n}=98,60,9 \%)$, a quase totalidade não teve financiamento $(\mathrm{n}=145,90,1 \%)$, com enfoque majoritariamente qualitativo $(n=52,32,4 \%)$, seguido pelos estudos quantitativos $(n=40,24,8 \%)$.

$\mathrm{O}$ tema de maior interesse tem sido atuação profissional, seguido pela saúde mental e análise de programas (18,6\%, 16,8\% e 11,8\%, respectivamente). A maioria das publicaçōes tem primeira autoria de mulheres, professoras universitárias, fora de grupos de pesquisa. A área com maior produção tem sido Saúde Coletiva ( $\mathrm{n}=51$, 31,6\%), seguido pela Psicologia $(n=36,22,4 \%)$. As revistas de divulgação são aquelas da Saúde Coletiva ( $n=69,42,9 \%)$ ou categorias profissionais isoladas $(n=57,35,4 \%)$, em revistas B1-B2 ( $n=80,49,6 \%)$, sem fator de impacto (tabela 1 ). 
Tabela 1. Características dos agentes e da produção científica sobre a saúde da população LGBT indexadas nas bases de dados Lilacs, Scielo, Web of Sciencee PubMedentre 2001 e 2018

\begin{tabular}{|c|c|c|c|}
\hline Variáveis & & $\mathbf{n}$ & $\%$ \\
\hline \multirow[t]{5}{*}{ País de Publicaçáo } & Brasil & 107 & 66,5 \\
\hline & Colômbia & 16 & 9,9 \\
\hline & Chile & 13 & 8,1 \\
\hline & México & 13 & 8,1 \\
\hline & Outros Países & 12 & 7,4 \\
\hline \multirow[t]{4}{*}{ Ano } & $2001-2005$ & 05 & 3,1 \\
\hline & $2006-2009$ & 19 & 11,8 \\
\hline & $2010-2013$ & 39 & 24,2 \\
\hline & $2014-2017$ & 98 & 60,9 \\
\hline \multirow[t]{2}{*}{ Financiamento } & Sim & 16 & 9,9 \\
\hline & Não & 145 & 90,1 \\
\hline \multirow[t]{6}{*}{ Tipo de Pesquisa } & Pesquisa Empírica Qualitativa & 52 & 32,4 \\
\hline & Pesquisa Empírica Quantitativa & 40 & 24,8 \\
\hline & Ensaio teórico/crítica política & 26 & 16,1 \\
\hline & Revisão & 24 & 14,9 \\
\hline & Relato de experiência/Estudo de caso & 13 & 8,1 \\
\hline & Pesquisa Empírica Quali-quanti & 06 & 3,7 \\
\hline \multirow[t]{5}{*}{ Grupo Estudado } & Apenas travestis e transexuais & 57 & 35,4 \\
\hline & Lésbicas, Gays e Bissexuais & 46 & 28,2 \\
\hline & LGBT/LGBTI & 34 & 21,2 \\
\hline & Apenas lésbicas e mulheres bissexuais & 16 & 9,9 \\
\hline & Apenas gays e homens bissexuais & 08 & 5,0 \\
\hline \multirow[t]{4}{*}{ Tema de interesse } & Competência e Atuação profissional & 30 & 18,6 \\
\hline & Saúde Mental & 27 & 16,8 \\
\hline & Políticas e Programas & 19 & 11,8 \\
\hline & Saúde Sexual e reprodutiva & 16 & 9,9 \\
\hline
\end{tabular}




\begin{tabular}{|c|c|c|c|}
\hline Variáveis & & $\mathbf{n}$ & $\%$ \\
\hline & Definição de Travestis e Transexuais & 15 & 9,3 \\
\hline & Violência e Discriminação & 14 & 8,7 \\
\hline & Serviços de saúde & 12 & 7,5 \\
\hline & Modificações corporais/hormonização & 11 & 6,8 \\
\hline & Currículo e Ensino & 08 & 5,0 \\
\hline & Temas Diversos & 09 & 5,6 \\
\hline \multirow[t]{2}{*}{ Gênero do primeiro autor } & Feminino & 88 & 54,7 \\
\hline & Masculino & 73 & 45,3 \\
\hline \multirow{4}{*}{$\begin{array}{l}\text { Filiação principal do } \\
\text { primeiro autor }\end{array}$} & Professor universitário & 80 & 49,7 \\
\hline & Estudante de pós-graduação & 58 & 36,0 \\
\hline & Pesquisador & 12 & 7,5 \\
\hline & Profissional/Gestor & 11 & 6,8 \\
\hline \multirow[t]{2}{*}{ Grupo de Pesquisa } & Sim & 21 & 13,0 \\
\hline & Não & 140 & 87,0 \\
\hline \multirow[t]{3}{*}{ Instituição } & Universidade & 134 & 83,4 \\
\hline & $\begin{array}{l}\text { Institutos de pesquisa não vinculados à } \\
\text { universidade }\end{array}$ & 15 & 9,4 \\
\hline & $\begin{array}{l}\text { Serviços/ Órgãos de Gestão/ ONG/ } \\
\text { Movimentos Sociais }\end{array}$ & 12 & 7,2 \\
\hline \multirow[t]{9}{*}{ Área de Publicação } & Saúde coletiva & 51 & 31,6 \\
\hline & Psicologia & 36 & 22,4 \\
\hline & Medicina diversas áreas & 20 & 12,4 \\
\hline & Psiquiatria & 14 & 8,7 \\
\hline & Enfermagem & 12 & 7,5 \\
\hline & Humanidades & 9 & 5,6 \\
\hline & Sociologia & 8 & 5,0 \\
\hline & Educação & 6 & 3,7 \\
\hline & Serviço Social & 5 & 3,1 \\
\hline
\end{tabular}




\begin{tabular}{llll}
\hline Variáveis & & $\mathbf{n}$ & $\%$ \\
\hline Tipo de Revista & Saúde coletiva & 69 & 42,9 \\
& De Categorias profissionais & 57 & 35,4 \\
& Interdisciplinares & 13 & 8,1 \\
& Área de saúde & 12 & 7,5 \\
& Específicas sobre gênero, sexualidades e & 10 & 6,2 \\
Qualis da revista em sua & minorias sexuais. & & \\
área de conhecimento & A1-A2 & 32 & 19,9 \\
& B1-B2 & 80 & 49,6 \\
Fator de Impacto da revista & Possui & 49 & 30,4 \\
& Náo Possui & 55 & 34,2 \\
\hline
\end{tabular}

Fonte: os autores, a partir da revisão sistemática nas bases selecionadas.

Os primeiros artigos encontrados sobre a saúde da população LGBT, que não fazem referência direta a infecção pelo HIV, datam de 2001 (ATHAYDE, 2001; RODRIGUEZ, 2001). De fato, o início dos anos 2000 marcou o fortalecimento do processo de construção social das demandas e direitos dessa população LGBT fora do espaço Aids (CARRARA, 2010; MELLO et al., 2011), tendo como marco no reconhecimento do Estado com a publicação do Programa Brasil sem Homofobia em 2004. Contudo, no espaço científico é apenas a partir de 2010 que ocorre um aumento no número de publicaçóes sobre a saúde LGBT, tendência anunciada nos trabalhos de Raimondi, Paulino e Teixeira (2016) e Carvalho (2014).

Nos primeiros dez anos, as pesquisas tratam da violência (ORTIZHERNÁNDEZ; GRANADOS, 2003), saúde mental (ORTIZ-HERNÁNDEZ; TORRES, 2005) e atuação profissional (GONZALEZ et al., 2004), expandindose para outros temas como saúde sexual e reprodutiva (BARBOSA; FACCHINI, 2009) e as definiçōes de travestis e transexuais (ARÁN; MURTA, 2009; ARÁN; ZAIDHAFT; MURTA, 2008), ao mesmo tempo, em que estudos passam ser publicados expressando tomadas de posiçáo dos agentes sobre o modelo das políticas de saúde em disputa, especialmente o processo transexualizador (LIONÇO, 2009).

Número muito reduzido de pesquisas explicitou financiamento direto, apenas 16 estudos, o que representa 9,9\% do total (tabela 1). Destes, 12 foram de instituiçóes 
púbicas, três da Organização das Naçóes Unidas e apenas um de instituiçôes privadas. Quanto aos tipos de estudo, a maior parte dos artigos apresenta resultados de pesquisas empíricas, com destaque para as análises qualitativas e com o uso da entrevista como técnica predominante. Entretanto, o número de ensaios teóricos e críticos foi pequeno, como também de revisôes, o que em alguma medida pode estar associado ao fato de ser um espaço em emergência e também, no caso brasileiro, ao surgimento relativamente recente, em 2008, de políticas e serviços de saúde específicos, como a portaria do processo transexualizador.

O grupo de lésbicas, gays e bissexuais - populaçôes definidas a partir da orientação sexual - em regra, foi alvo de estudos em separado da população de travesti e transexuais, esta definida a partir da identidade de gênero. Apenas $21,1 \%$ tomaram o grande grupo LGBT como objeto de investigação. Para o grande grupo, a sigla LGBT foi a mais utilizada, poucos estudos utilizaram suas variaçôes como LGBTT (FERNANDES, 2017) e LGBTI (MONTOYA; SÁNCHEZ-ALFARO, 2011).

Vale destacar que a bissexualidade não está presente em todas as pesquisas, mesmo em pesquisas estruturadas a partir da orientação sexual. Chama a atenção ainda, o baixo número de trabalhos que tratam exclusivamente de homens gays e bissexuais, fato possivelmente relacionado à seleção que excluiu os estudos sobre HIV/Aids, que tem mais se debruçado sobre este subgrupo.

Em relação aos objetos de pesquisa, foram identificados dez grandes temas de interesse, sendo os elementos da competência e atuação profissional os mais pesquisados. Logo abaixo estão os pontos de vista sobre a saúde mental, os estudos de políticas e programas, as questôes referentes à saúde sexual e reprodutiva, e as pesquisas sobre a definição de travestis e transexuais (tabela 1). A descrição detalhada do ponto de vista presente em cada um desses temas encontra-se no quadro 1.

\section{Os agentes e os locais de publicação sobre a saúde LGBT}

Quanto aos agentes, a maior parte dos primeiros autores é do gênero feminino (tabela 1), como também, é maior o interesse de autores desse gênero pelos temas de serviços de saúde, das políticas e programas, e das práticas sexuais e reprodutivas, vale lembrar, que, neste último tema, boa parte das pesquisas volta-se para as mulheres lésbicas e bissexuais (tabela 2, tabela 3). Os professores e estudantes universitários também são maioria. Contudo, são poucos os autores vinculados a grupos de pesquisa, realidade esperada para um espaço social de pesquisa recente, e por esse 
motivo, pouco estruturado. Houve menção nos artigos a 15 grupos de pesquisa, sendo 11 brasileiros.

Notam-se grupos de pesquisa voltados a objetos de pesquisa específicos, com destaque para a violência, gênero e sexualidades, e, por fim, grupos das áreas de Saúde Coletiva, Psicologia, Psiquiatria e Enfermagem. A presença de agentes vinculados a essas grandes áreas também pode ser percebida pelos tipos de revista onde os artigos foram publicados.

As revistas da área de Saúde Coletiva mostram-se como o lócus privilegiado de publicação, em segundo lugar, estâo as revistas de categorias profissionais específicas, com destaque para revistas de Psicologia e Enfermagem (tabela 1). Cinco revistas da área de Saúde Coletiva (Ciência \& Saúde Coletiva, Physis: Revista de Saúde Coletiva, Cadernos de Saúde Pública, Saúde e Sociedade e Tempus) abarcam 27\% de todas as publicaçôes, num universo de 100 revistas listadas. As revistas de gênero e sexualidades, por sua vez, ainda não se configuram como locais importantes para a divulgação das evidências sobre a saúde LGBT.

Quando esta análise se desdobra para as grandes áreas, o polo dominante dos agentes é ocupado por agentes da Psicologia e da Saúde Coletiva (com as áreas de Saúde Pública e Serviços de Saúde). Enfermagem e Medicina também se mostram com destaque (tabela 1).

Dos artigos do campo médico, a Psiquiatria tem sido dominante, especialmente nos estudos publicados no México e Colômbia. O interesse da Medicina e das ciências psi (psiquiatria, psicologia e psicanálise), ao menos pela transexualidade, já havia sido apontado pelos estudos de Almeida e Murta (2013). Especialidades como Endocrinologia, Cirurgia Geral e Neurologia começam a se interessar finalmente pelos temas referentes à definição e a transformação corporal de pessoas transexuais, como também, a ginecologia na assistência a mulheres lésbicas e bissexuais. Nota-se também a chegada de novos agentes oriundos de diversos subespaços do campo científico, inclusive de áreas mais distantes da saúde, como direito, linguística e sociologia.

Ainda sobre os agentes, ao explorar a relação dos dois grupos dominantes, a Saúde Coletiva e a psicologia, com os postos de vista, percebe-se que os agentes da Saúde Coletiva ocupam a autoria da maioria das pesquisas sobre os programas e serviços, ainda tem destaque no tema de práticas sexuais e reprodutivas, neste dividem o interesse com a enfermagem e a medicina. 
Quadro 1. Conteúdo textual dos pontos de vista identificados na produção científica entre 2001 e 2018 no espaço LGBT sobre a saúde da população LGBT

\begin{tabular}{|c|c|}
\hline Ponto de Vista & Análise Substancial dos Pontos de Vista \\
\hline $\begin{array}{l}\text { Competência } \\
\text { e atuaçáo } \\
\text { profissional }\end{array}$ & $\begin{array}{l}\text { Abordam a dificuldade que os profissionais de saúde, com destaque para } \\
\text { enfermeiros, médicos, ACS e psicólogos, possuem para atuar junto às questôes } \\
\text { de saúde da população LGBT. Evidenciam práticas discriminatórias e não } \\
\text { qualificadas que produzem exclusâo e violência. De um modo geral, sustentam seus } \\
\text { argumentos na concepção de heteronormatividade, como norma que estrutura a } \\
\text { atuaçấo profissional, e nos conceitos de ética e bioética. Há uma maior presença } \\
\text { de estudos sobre a relação entre as mulheres lésbicas e os profissionais de saúde no } \\
\text { que diz respeito à saúde ginecológica, e a atuação de psicólogos nos diversos grupos. } \\
\text { As principais categorias analisadas são conhecimentos, práticas, discursos, atitudes } \\
\text { e representaçôes sociais. Um reduzido número de estudos descreve condutas ou } \\
\text { opçôes terapêuticas, notadamente, para a atuaçâo de psicólogos e geralmente } \\
\text { relacionadas a pessoas trans. }\end{array}$ \\
\hline Saúde Mental & $\begin{array}{l}\text { Documentam importantes disparidades em saúde mental na comparaçáo da } \\
\text { populaçáo LGBT a seus pares heterossexuais e cisgêneros. Os estudos são categóricos } \\
\text { em demonstrar a determinação social da orientação sexual e da identidade gênero } \\
\text { no maior risco para problemas em saúde mental. As principais categorias estudadas } \\
\text { são ideaçáo suicida, tentativa de suicídio, uso de drogas lícitas e ilícitas, sintomas } \\
\text { depressivos, ansiedade e autoestima. A relaçáo entre a vivência de discriminação } \\
\text { e violências com o sofrimento psíquico é amplamente explorada por diversas } \\
\text { abordagens metodológicas. As violências são apontadas como os principais fatores } \\
\text { para os problemas de saúde mental dessa população. Destacam a necessidade de } \\
\text { abordagens específicas para a atençáo à saúde mental da populaçáo LGBT, com } \\
\text { destaque para adolescentes e jovens. }\end{array}$ \\
\hline $\begin{array}{l}\text { Estudos sobre } \\
\text { políticas e } \\
\text { programas }\end{array}$ & $\begin{array}{l}\text { Analisam os avanços, os impasses e os desafios na formulação e na implementação das } \\
\text { políticas e programas voltados para a população LGBT. Há um maior interesse pelo } \\
\text { estudo do Processo Transexualizador, ficando a Política Nacional de Saúde Integral } \\
\text { e os programas locais, num segundo plano. Os achados centram-se na fragilidade e } \\
\text { insuficiência das ações implementadas, em contraposição as importantes conquistas } \\
\text { no âmbito normativo da política de saúde. As políticas de saúde mostram-se mais } \\
\text { consolidadas quando comprados com outras áreas como segurança e educação. Em } \\
\text { relação ao processo Transexualizador os esforços são direcionados para a discussão } \\
\text { das normas utilizadas pelas portarias, destacando seu caráter ora excludente, ora } \\
\text { estratégico na consolidação do direito a saúde de pessoas travestis e transexuais. }\end{array}$ \\
\hline
\end{tabular}




\begin{tabular}{|c|c|}
\hline Ponto de Vista & Análise Substancial dos Pontos de Vista \\
\hline $\begin{array}{l}\text { Saúde sexual e } \\
\text { reprodutiva }\end{array}$ & $\begin{array}{l}\text { Apresentam dados tanto da dimensão da atenção à saúde sexual e reprodutiva, como } \\
\text { das práticas sexuais e reprodutivas. No âmbito da atenção, revelam importantes } \\
\text { barreiras de acesso aos cuidados de saúde, com uma assistência frágil e insuficiente, } \\
\text { ainda permeada por preconceitos e discriminaçóes. As infecções sexualmente } \\
\text { transmissíveis ainda dominam os objetos de estudo, numa abordagem que privilegia } \\
\text { as práticas sexuais consideradas de risco, especialmente em homens gays; e a } \\
\text { invisibilidade da abordagem das práticas sexuais pelos profissionais, no caso das } \\
\text { mulheres lésbicas. As pesquisam mostram maiores vulnerabilidades deste grupo em } \\
\text { relaçáo a sua saúde sexual, quando comparas a populaçấo heterossexual. Por outro } \\
\text { lado, estudos recentes mostram avanços no planejamento reprodutivo, notadamente, } \\
\text { de mulheres lésbicas, em contraposição a invisibilidade da reprodução nos grupos de } \\
\text { travestis e transexuais. }\end{array}$ \\
\hline $\begin{array}{l}\text { Definição de } \\
\text { Travestis e } \\
\text { Transexuais }\end{array}$ & $\begin{array}{l}\text { Apresentam as discussões que envolvem a definição das pessoas travestis e transexuais, } \\
\text { evidenciado as disputas entre a interpretação nosológica que inclui os diagnósticos de } \\
\text { Disforia de Gênero no DSM-5 e de Transexualismo no CID-10, e a interpretação } \\
\text { sociocultural que compreende essas pessoas a partir de suas experiências, apoiada } \\
\text { nos conceitos de gênero e identidade. A maior parte dos estudos fundamentada nas } \\
\text { teorias de gênero e na teoria queer, problematiza a patologização da transexualidade, } \\
\text { que para a medicina e as algumas abordagens das ciências psi (psiquiatria, psicologia } \\
\text { e psicanálise) constitui uma desordem mental. Destacam que a identidade de } \\
\text { gênero diz respeito à percepção subjetiva de ser masculino ou feminino, ao senso de } \\
\text { pertencimento a um ou outro gênero, conforme os atributos, os comportamentos e os } \\
\text { papéis convencionalmente estabelecidos para homens e mulheres, não sendo possível } \\
\text { entâo incorporar o gênero como uma categoria diagnóstica. Ainda há estudos que } \\
\text { advoguem pelo uso estratégico do diagnóstico para acesso aos sistemas de saúde } \\
\text { e estruturam de serviços. E um pequeno número de trabalhos busca solidificar as } \\
\text { definiçóes nosológicas apontando evidências para apoiar o diagnóstico a partir da } \\
\text { neuroanatomia, genética e psicanálise. }\end{array}$ \\
\hline $\begin{array}{l}\text { Modificaçóes } \\
\text { corporais }\end{array}$ & $\begin{array}{l}\text { Apresentam dados sobre as técnicas mais usadas para modificaçôes corporais com } \\
\text { destaque para a hormonizaçáo. Também revelam dados sobre os efeitos danosos dos } \\
\text { silicones industriais. Já sobre as cirurgias de transgenitalização, demonstram que a } \\
\text { busca pela mudança da genitália não é unânime entre pessoas transexuais. Logo, } \\
\text { os protocolos de atendimento à saúde trans não devem compreender a redesignação } \\
\text { sexual como o único desfecho nos processos de transição no gênero. Ainda há } \\
\text { os estudos que abordam os benefícios das intervençôes cirúrgicas e hormonais. } \\
\text { Outros trabalhos destacam as relaçôes entre corpo, saúde e dispositivos médicos, } \\
\text { argumentando a divergência entre as compreensóes de saúde e doença produzidas } \\
\text { pelos poderes e saberes biomédicos sobre os corpos trans e aquelas que as pessoas } \\
\text { trans produzem sobre si mesmas, sobretudo em programas de atenção à saúde } \\
\text { específica, como os do processo transexualizador. }\end{array}$ \\
\hline
\end{tabular}

continua... 


\begin{tabular}{|c|c|}
\hline Ponto de Vista & Análise Substancial dos Pontos de Vista \\
\hline $\begin{array}{l}\text { Violência e } \\
\text { Discriminação }\end{array}$ & $\begin{array}{l}\text { Destacam a violência e a discriminaçáo motivadas por homofobia como uma } \\
\text { manifestação específica de violência que se manifesta em diversos espaços como a } \\
\text { escola, a família, os serviços de saúde e as instituições de segurança. A maior parte } \\
\text { dos estudos encontrou altos níveis de discriminação e vitimização percebida, com } \\
\text { impacto significante na saúde desse grupo, especialmente na saúde mental. Os } \\
\text { estudos mostram índices diferentes de discriminação e violência entre os membros } \\
\text { da população LGBT, onde homens gays e bissexuais foram vítimas de violência } \\
\text { com mais frequência do que as mulheres bissexuais e lésbicas pesquisadas, } \\
\text { contudo, para a maior parte das discriminaçóes e agressôes, travestis e transexuais } \\
\text { encontram-se no topo da escala de vitimizaçáo. Outras diferenças por localizaçáo } \\
\text { geográfica, raça, expressóes de gênero e condição socioeconômica também foram } \\
\text { demonstradas. Neste ponto de vista ainda há interesse sobre as questões políticas } \\
\text { que envolvem a problemática da violência contra LGBT e formas de atuação. }\end{array}$ \\
\hline $\begin{array}{l}\text { Serviços de } \\
\text { saúde }\end{array}$ & $\begin{array}{l}\text { Estudam o acolhimento e o acesso da população LGBT aos diversos serviços } \\
\text { de saúde. As principais barreiras encontradas no acesso desse grupo foram de } \\
\text { cunho sociocultural e referente aos profissionais. Outros resultados demonstram } \\
\text { dificuldades dos serviços em acolherem as demandas dessa população, seja pela } \\
\text { falta de conhecimentos específicos ou ainda pela invisibilização das mesmas } \\
\text { na organizaçáo dos serviços, ainda organizados numa lógica heteronormativa. } \\
\text { Também se encontram diversos relatos de experiências de implantação de serviços } \\
\text { específicos para a população LGBT ou estratégias utilizadas para promover um } \\
\text { acolhimento adequado. }\end{array}$ \\
\hline $\begin{array}{l}\text { Currículo e } \\
\text { ensino }\end{array}$ & $\begin{array}{l}\text { Ocupam-se da avaliação da homofobia e atitudes discriminatórias de estudantes } \\
\text { da área da saúde em relação à homossexualidade e à transexualidade. As } \\
\text { investigações demonstram não somente altas taxas de rejeição e atitudes } \\
\text { preconceituosas e discriminatórias, mas também, significativos erros conceituais } \\
\text { em relação a esse grupo. Um pequeno número de trabalhos relata açốes } \\
\text { direcionadas para reverter o problema. }\end{array}$ \\
\hline $\begin{array}{l}\text { Temas } \\
\text { Diversos }\end{array}$ & $\begin{array}{l}\text { Retratam questōes metodológicas das pesquisas como as dificuldades encontradas } \\
\text { no uso das categorias orientação sexual, identidade de gênero e práticas sexuais } \\
\text { no campo científico. Descrevem modelagens e estratégias para garantir boas } \\
\text { evidências. Abordam outras questôes de saúde a exemplo do conhecimento sobre } \\
\text { tuberculose em travestis e demandas gerais de saúde }\end{array}$ \\
\hline
\end{tabular}

Fonte: os autores, a partir da revisão sistemática nas bases selecionadas. 
| Página 16 de 31

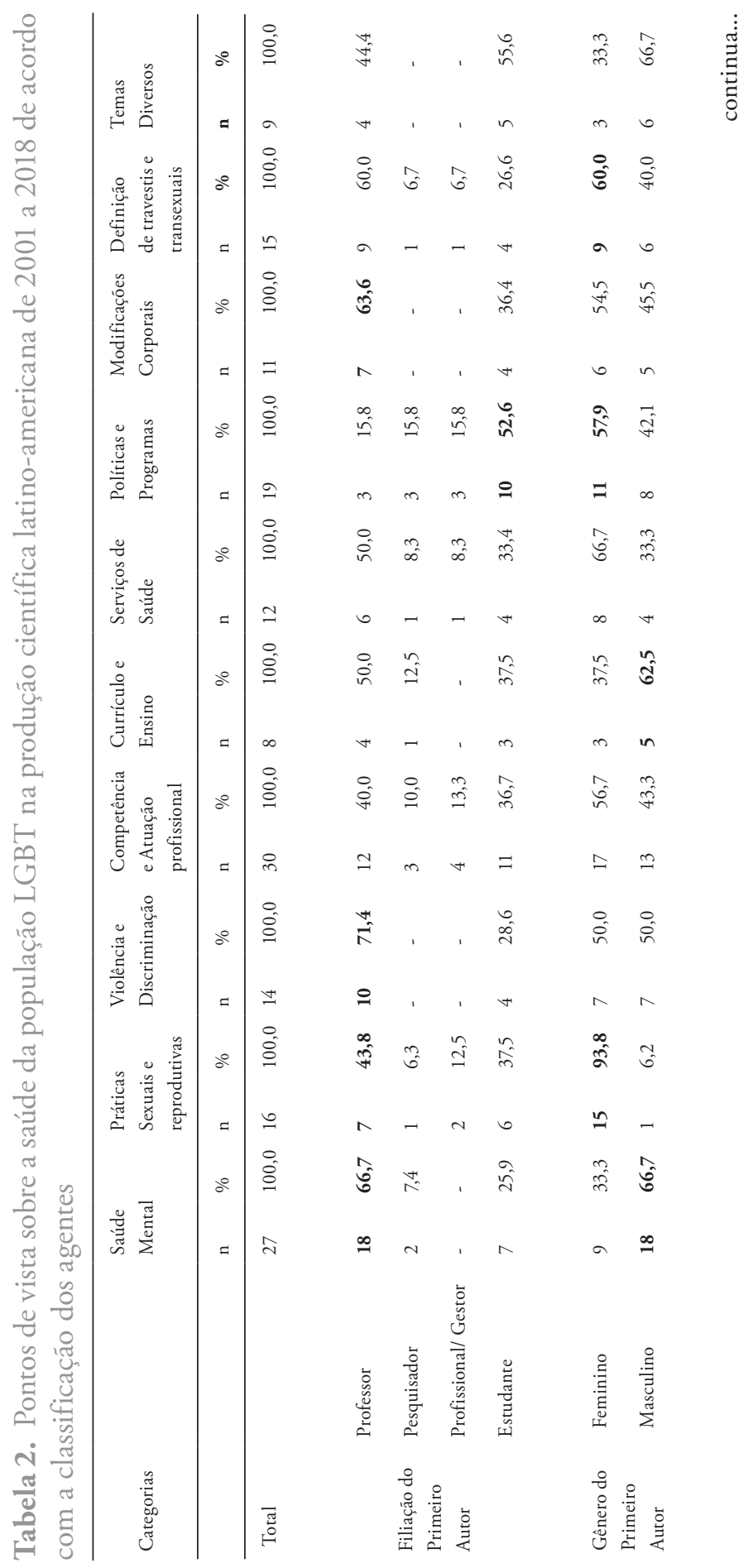


| Página 17 de 31

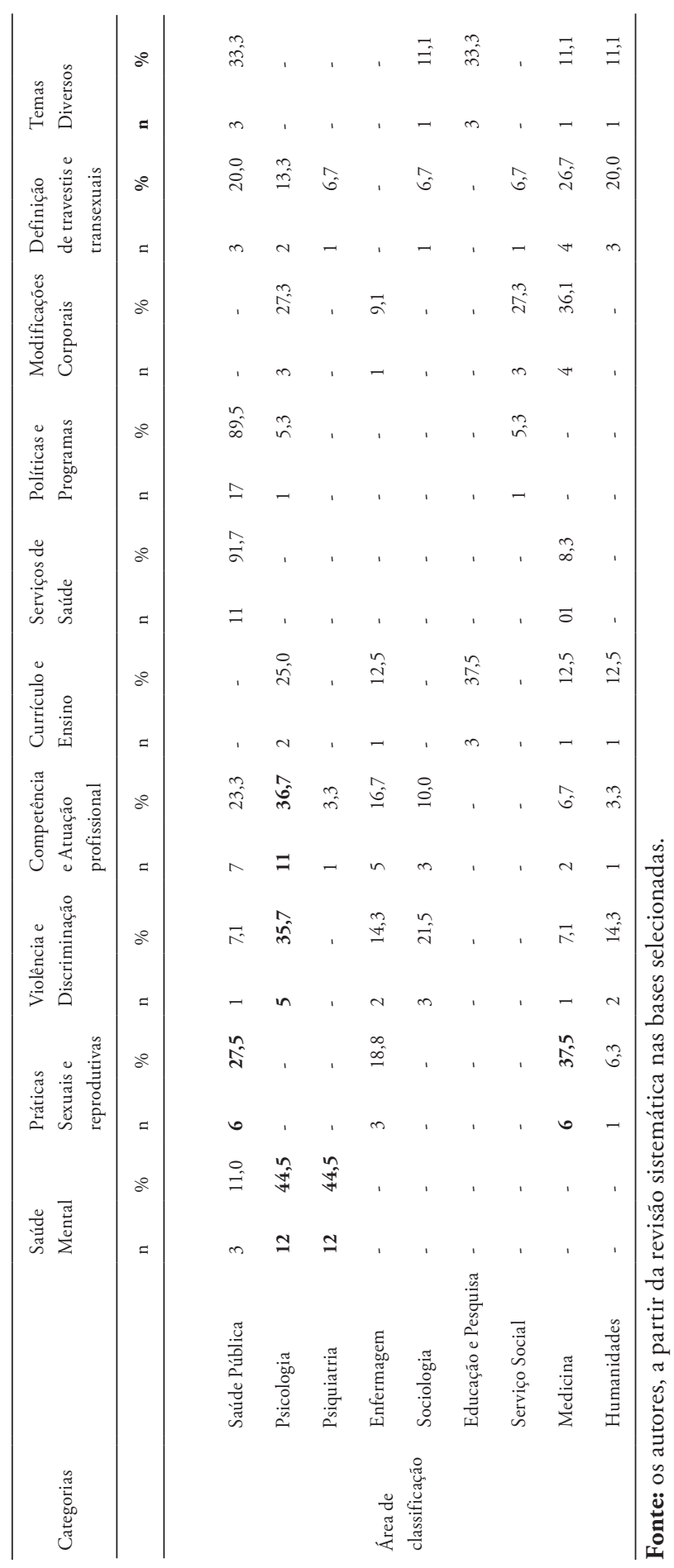




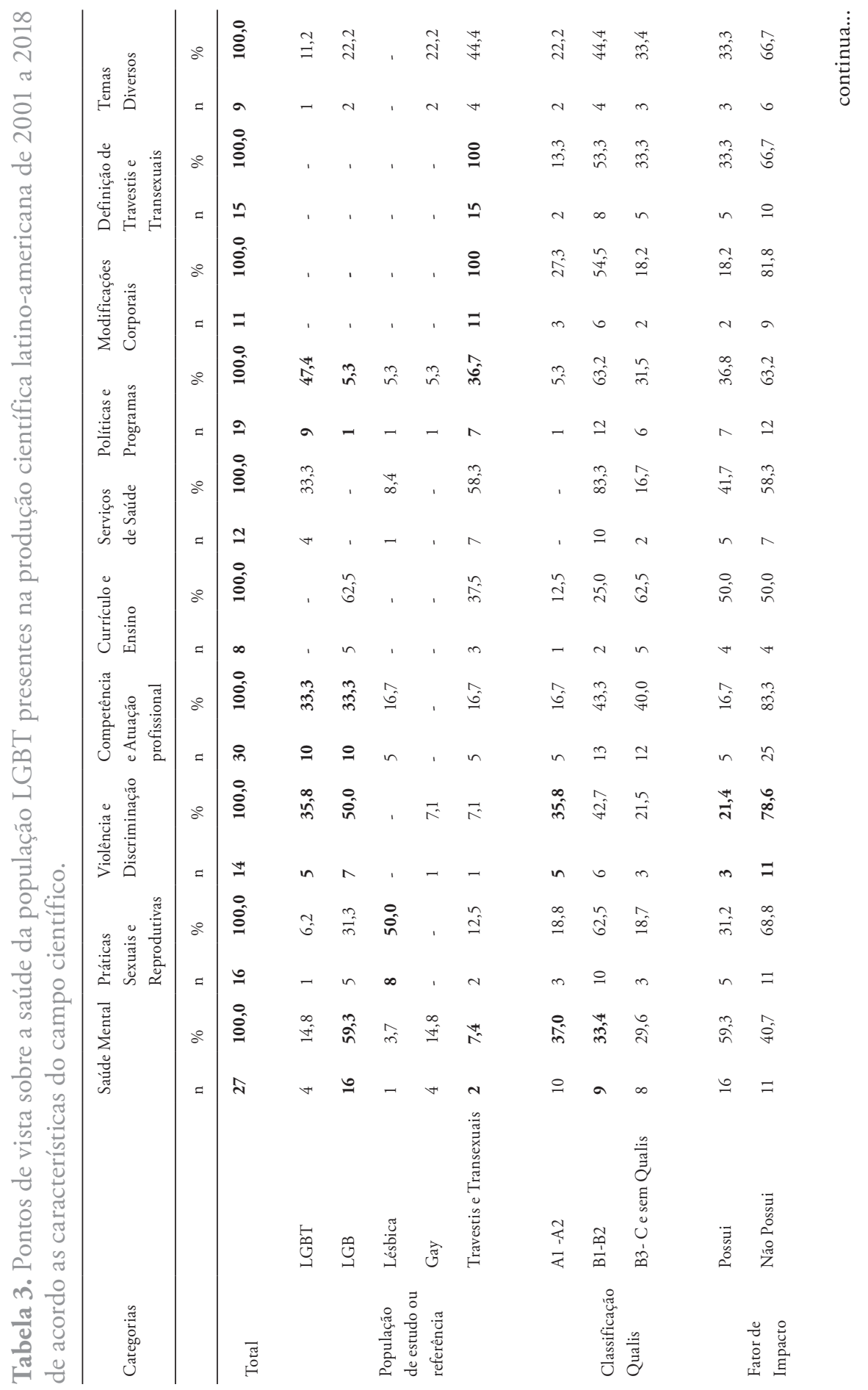


| Página 19 de 31

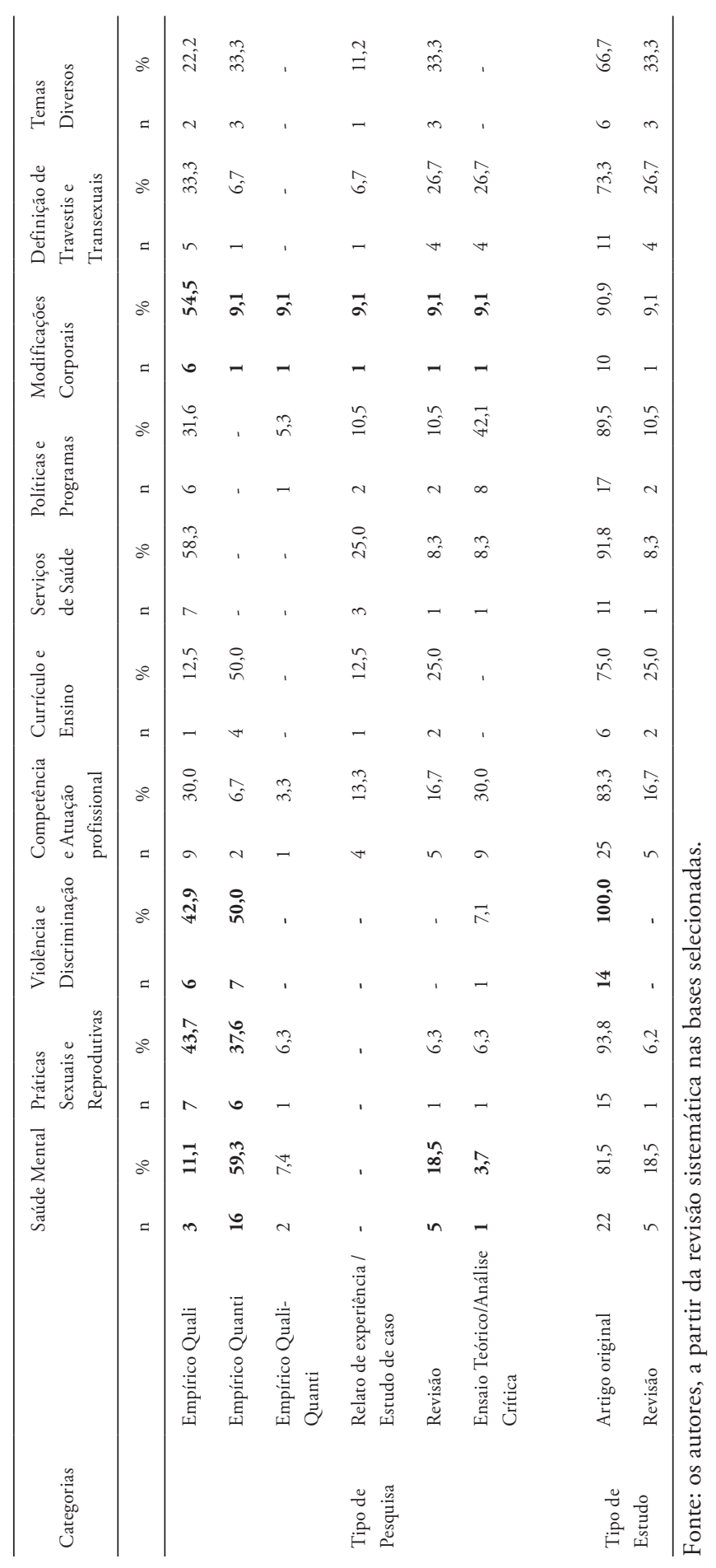


Já os agentes vinculados à Psicologia são maioria nos trabalhos sobre saúde mental, onde também há uma presença da psiquiatria. No tema de violência e discriminação, estes dividem o interesse com a sociologia. Os estudos sobre competência e atuação profissional é tema mais diversificado no que se refere às áreas interessadas (tabela 2).

Entre as instituiçóes, a universidade é quem mais participa desse espaço, tendo destaque a UERJ, a USP e a UnB. Outro importante agente institucional que se apresenta na estrutura deste espaço é a Fiocruz que junto com a UERJ, foram as instituiçôes com maior produção.

\section{O espaço dos pontos de vista}

$\mathrm{Na}$ análise da posição de cada um dos pontos de vista no espaço estudado, as temáticas de interesse do grupo de pesquisadores de maior capital científico, os professores universitários, tem sido a saúde mental 66,7\%), violência e discriminação definição de travestis e transexuais, saúde mental, violência e discriminação, além de transformaçóes corporais (tabela 2).

Ainda considerando o capital científico e reconhecimento dos pares, este avaliado a partir da qualidade da revista de publicação pela classificação do Qualis/CAPES (tabela 3), saúde mental, violência e discriminação, e transformaçôes corporais mantem-se em posiçôes dominantes na definição do que é importante conhecer e saber sobre saúde LGBT. Quando o critério utilizado é o fator de impacto, os temas publicados em revistas com fator de impacto, além de saúde mental e violência e discriminação, altas taxas foram encontradas para práticas sexuais e reprodutivas, currículo e ensino, e estudos sobre serviços.

Quanto aos métodos científicos, é importante observar os temas que já despertam interesse por revisões de literatura, o que demonstra tanto a expansão do interesse entre outros pesquisadores pelo tema, como a presença de pesquisas em outros países que dão conta de produzir tais estudos. Como objetos de revisões os temas saúde mental, definição da transexualidade, currículo e ensino, e competência e atuação profissional.

Sobre o uso dos métodos dominantes de pesquisa na área da saúde, a saber, as pesquisas empíricas, os temas mais presentes são saúde mental, violências e discriminação, práticas sexuais e reprodutivas, e transformaçóes corporais. Se o recorte considerar apenas a pesquisa quantitativa, o polo dominante da pesquisa 
empírica, a saúde mental e a violência e discriminação continuam no topo da hierarquia, geralmente realizado sob a forma de inquérito.

Nas pesquisas qualitativas, os temas mais presentes foram serviços de saúde, modificaçôes corporais, violência e discriminação, e práticas sexuais e reprodutivas. A técnica mais presente foi a entrevista, poucos estudos utilizaram observação participante, grupos focais, ou até estudos etnográficos clássicos. Aqui é importante destacar que entre os métodos mais dominados na área da pesquisa em saúde, como ensaios teóricos e análises críticas, os temas mais envolvidos em disputas políticas, como a definição de travestis e transexuais e os estudos sobre políticas e programas ocupam espaço relevante.

Essa diferenciação entre os temas de interesse sobre a saúde da população LGBT demonstra que na hierarquia de suas posiçôes das publicaçôes latino-americanas, a problemática da saúde mental é a que ocupa o polo dominante, pois é ponto vista elaborado pelos pesquisadores de maior prestígio, utiliza os métodos mais reconhecidos, e é publicado em revistas de maior qualidade. Contudo, na investigação do conteúdo textual dos temas (quadro 1) onde está descrito o ponto de vista; com seus prognósticos, problemas, questóes, e possíveis soluçóes; percebe-se que a violência é a questão mais presente, por ser uma categoria transversal e explicativa de grande parte das evidências produzidas. Os estudos sobre saúde mental, currículo e ensino, atuação e competência profissional, estão atravessados fundamentalmente pelas questôes de homofobia, discriminação, preconceitos e violências.

Com efeito, o exame dos descritores mais utilizados em todo o período, considerando os descritores que tratam da dimensão da saúde, percebe-se, que entre aqueles com mais de cinco citaçôes, a prevalência da homofobia e da violência com 22 e 14 citaçôes, respectivamente: homofobia $(n=25)$, violência $(n=17)$, saúde $(n=14)$, comportamento sexual $(\mathrm{n}=13)$, Saúde Mental $(\mathrm{n}=10)$, saúde sexual e reprodutiva $(n=9)$, políticas públicas $(n=8)$, discriminação $(n=8)$, suicídio $(n=7)$, SUS $(n=7)$.

Nota-se também que estes objetos mantém uma relação direta com o grupo em estudo, os estudos sobre saúde mental e violência comportam todo o conjunto de orientações sexuais não heterossexuais (gays, lésbicas, bissexuais). Já pesquisas sobre saúde sexual e reprodutiva abarcam principalmente mulheres lésbicas, por fim, os transexuais e as travestis aparecem quase que exclusivamente vinculados aos temas de transformaçôes corporais, de definição de travestis e transexuais e nos estudos sobre políticas e programas (tabela 3). 
O resultado é praticamente um quadro estático onde para cada grupo considerado há um ponto de vista que advogue sobre qual o problema de saúde merece, de fato, esforços de objetivação. Em que pese a análise substancial dos artigos mostrar importantes achados para o grupo de homens gays nos resultados para saúde mental e violência e discriminação, sua reduzida presença em todos os temas, num cenário de exclusão dos estudos de HIV/Aids, merece menção.

\section{A disputa pela classificação: sexualidade e gênero}

A constituição do grupo que pode ser reconhecido como LGBT, ou ainda, em um de seus subgrupos como gays, lésbicas, bissexuais, travestis e transexuais, por se tratar de um trabalho de classificação social, depende de um trabalho coletivo de construção inseparavelmente teórico e prático, que visa, em última instância, a consagração simbólica necessária para justificar especialmente as ações do Estado (BOURDIEU, 2014a).

No trabalho de constituição, definição, categorização e por fim, nomeação universal, o campo científico exerce um papel fundamental, especialmente para os grupos onde está nomeação está em franca disputa (BOURDIEU, 2014b), como é o caso da população LGBT. Diversos estudos destacam a diversidade de termos utilizados para designar essa população e sua relação com contextos sociais mais amplos (MAHER et al., 2009; BENTO, 2017; CARVALHO; CARRARA, 2013).

Se por um lado está bem estabelecida à separação entre os grupos formados por questôes de sexualidades/orientação sexual (LGB) e gênero/identidade de gênero (travestis, transexuais), internamente há importantes lutas sobre o princípio que definem esses grupos.

No caso das questôes ligadas a sexualidade, os artigos apresentam três princípios diferentes de classificação: a orientação sexual, as práticas sexuais e a identidade sexual. Os estudos que utilizam a orientação sexual, como categoria de definição, baseiam-se no comportamento sexual, independente do ato sexual em si, tratam prioritariamente de uma preferência em termos de atração e relaçóes sexuais, afetivas ou emocionais. São pesquisas que constituem esse grupo em oposição ao grupo heterossexual, buscando apresentar diferenças em termos de maior risco ou vulnerabilidade, as pesquisas, por vezes, utilizam recursos de escalas destacando orientação sexual como um gradiente que passa pela bissexualidade (TEIXEIRAFILHO; RONDINI, 2012; NATARELLI et al., 2015). 
Ainda que estes estudos destaquem a necessidade de autoafirmação, ou seja, o indivíduo precisa afirmar o comportamento sexual ou ter demonstrado por algum outro meio, como registro anterior em prontuários ou pelo uso de sites, não é colocada à necessidade de afirmação enquanto gay, lésbica ou bissexual, ainda que estes termos possam ser usados, a categoria do comportamento ou desejo é o ponto central.

O princípio das práticas sexuais é a nomeação com menor força, define os grupos em HSH (homem que fazem sexo com homens) e MSM (mulheres que fazem sexo com mulheres), considera para seu uso as dificuldades de operacionalização na pesquisa dos demais conceitos, como também, a disjunção entre desejos, práticas e identidades que geram variaçóes das parcerias sexuais e do seu padrão de ocorrência ao longo da vida, realidade que categorias mais homogêneas podem excluir (BARBOSA; FACCHINI, 2009). Notadamente, neste estudo, esta forma de nomeação foi encontrada em pesquisas sobre saúde sexual e reprodutiva e realizados com a população feminina (ASSIS; GOMES; PIRES, 2014; SILBERMAN; BUEDO; BURGOS, 2016; BERTOLIN et al., 2010). Necessário destacar o amplo uso nas pesquisas sobre HIV do HSM e MSM em populaçôes masculinas (MORA; BRIGEIRO; MONTEIRO, 2018), tema que também faz referência à saúde sexual.

A identidade sexual traz consigo a especificidade da apresentação pública da orientação sexual, não se resume ao modo como o indivíduo percebe-se, mas como ele expressa-se no mundo social. Faz referência a um estilo de vida, o que inclui lugares comuns de convivência, compartilhamento de uma cultura, e a identificação com um determinado grupo, o que gera a necessidade da autoafirmação. Sua diferença em relação à orientação sexual não está na definição, mas na ideia de assumir-me como grupo, de pertencimento, de identidade (ARAUJO; PENNA, 2014).

Esta nomeação está mais em estudos de saúde mental e nos estudos sobre políticas e programas, mas também naqueles que recrutam seus sujeitos em ONGs, movimentos sociais ou locais públicos, como as paradas do orgulho e os espaços de convivência, na produção de seus dados. De um modo geral esses estudos usam as expressóes gays, lésbicas e bissexuais, ou ainda, a sigla LGBT quando inclui as pessoas travestis e transexuais (PERUCCHI; BRANDAO; VIEIRA, 2014; LOZANO-VERDUZCO; FERNÁNDEZ-NIÑO; BARUCH-DOMÍNGUEZ, 2015; BARRIENTOS et al., 2017; PEREIRA et al., 2017). 


\section{A disputa entre a identidade gênero e o diagnóstico médico}

Se nas questôes de sexualidade, a definição da homossexualidade como patologia já vem sendo superado desde os anos 70, para transexuais essa disputa ainda permanece. A nomeação de transexualismo, de acordo o CID-10 ou de Disforia de Gênero segundo o DSM-5, utiliza um diagnóstico psiquiátrico para a definição, onde há uma inconformidade entre o sexo, dado natural, biológico, norma por excelência de definição, e o gênero (ARÁN; MURTA; LIONÇO, 2009; FRANCO et al., 2010). Em ambos os diagnósticos, há um transtorno que necessita de tratamento, intervenção e correção, obedecendo a uma lógica de normalidade e de linearidade entre sexo, gênero e sexualidade (ARÁN; MURTA; LIONÇO, 2009; FRANCO et al., 2010).

A nomeação que utiliza o diagnóstico psiquiátrico para definir esses grupos, define transexualismo masculino como o indivíduo 46, XY com fenótipo masculino normal que deseja viver e ser aceito como membro do sexo feminino, já o Transexualismo Feminino refere-se ao indivíduo 46, XX com fenótipo feminino normal que deseja viver e ser aceito como membro do gênero feminino (COSTA; MENDONÇA, 2014). É exatamente o oposto da nomeação que toma como referência as questóes ligadas à identidade de gênero.

Nesta outra categorização, as mulheres transexuais são aqueles indivíduos que se identificam como mulheres, e homens transexuais os que se identificam homens. Baseia-se no questionamento da lógica hegemônica onde o sexo biológico determina a identidade de gênero. A identidade de gênero diz respeito à percepção subjetiva de ser masculino ou feminino, ao senso de pertencimento a um ou outro gênero, conforme os atributos, os comportamentos e os papéis convencionalmente estabelecidos para homens e mulheres (BENTO, 2006).

É uma nomeação onde os modos de subjetivação ou a diversidade das formas de construção de gênero estão no centro da definição, questionando o aspecto psiquiátrico ou patologizante das definiçóes médicas. Ainda que um conjunto de termos possa ser usados: transexuais, transgêneros, pessoas trans, há uma concordância no sentido de que a transexualidade é uma experiência de conflito com as normas de gênero que estabelecem, socialmente, a anatomia da genitália para definir homem e mulher ${ }^{60}$. Condição marcadamente diferente daquele presente no diagnóstico médico e psiquiátrico.

Estudos que utilizam o diagnóstico psiquiátrico pertencem às áreas médicas, psiquiatria, endocrinologia, cirurgia (FRANCO et al., 2010; SPIZZIRRII, 2012; 
ATHAYDE, 2001) mas também a alguns agentes da psicologia, com destaque para a psicanálise (RINALDI, 2011). Apoiados em estudos seminais como o clássico O fenômeno Transexual de Harry Benjamin, mantém seu interesse sobre as questôes relacionadas às modificaçóes corporais das pessoas transexuais, um pequeno número de estudos focaliza questôes relacionadas a causa ou a origem da transexualidade.

Já os trabalhos que questionam a norma biológica de definição do gênero, apoiados em conjunto de autores, com destaque para M. Foucault e J. Butler, buscam a produção de um conjunto de evidências, a partir dos mais diversos métodos, que dê conta de mostrar as limitaçóes e arbitrariedades da psiquiatrização da transexualidade. Esta disputa é sem dúvida uma das principais lutas do campo científico. A recente mudança aprovada para o CID-11, em que o diagnóstico de transexualismo deixa o capítulo de transtornos mentais e passa a ser localizado no capítulo sobre as condiçóes relacionadas à saúde sexual, mostra sinais claros desse fato.

Vale destacar que o mesmo repete-se para a categoria travesti, ainda que exista uma concordância no espaço da produção científica que esta categoria traz diferenças em relação à transexualidade, enquanto a nomeação médica utiliza os CIDs travestismo fetichista e travestismo bivalente para nomeá-la, o campo das ciências sociais e humanas em saúde destaca as travestis como pessoas na fronteira de gênero, que participam do universo feminino e que podem ser pensadas dentro do conjunto de pessoas trans (LIONÇO, 2009).

Todas essas lutas em torno das nomeaçôes apresentam-se mais uma vez na análise dos descritores para essa população. As dicotomias entre transexualidade e transexualismo, ou variaçóes entre homossexualidade feminina, lésbicas e MSM, mostram-se presentes.

Chamou a atenção a repetição para os descritores com cinco ou mais citaçóes, a saber: homossexualidade $(n=39)$, identidade de gênero $(n=15)$, pessoas transgênero $(\mathrm{n}=15)$, transexualismo $(\mathrm{n}=15)$, gênero (14), transexualidade $(\mathrm{n}=12)$, homossexualidade feminina $(n=9)$, LGBT $(n=9)$, lésbica $(n=8)$, travesti $(n=6)$, orientação sexual $(n=6)$, homossexualidade masculina $(n=5)$, minorias sexuais $(n=6)$ e gay $(n=5)$.

\section{Considerações finais}

A análise da produção científica revelou que é possível sugerir a emergência de um espaço científico, em diferenciação dos convencionais estudos de gênero e saúde, 
sexualidade e saúde, e HIV/Aids, onde a saúde da população LGBT é o objeto central. Este espaço emergente na América Latina, desde 2001 com um grande incremento em 2014, é ocupado principalmente por agentes da Saúde Coletiva, Psicologia, Enfermagem e Psiquiatria. Neste espaço, a questão da violência e da discriminação e seu impacto na saúde mental, no ensino e na atuação profissional aparecem como principais temas de interesse.

Destaca-se que os objetos de pesquisa legítimos se mostram diferentes para cada um dos subgrupos. Lésbicas, gays, travestis e transexuais são alvos de objetos diferentes, ao passo que, a própria definição do grupo e como classificá-los segue em franca disputa, especialmente, a categoria da transexualidade em oposição ao transexualismo.

O presente estudo não aprofundou a análise da posição e da tomada de posição dos agentes, das condiçóes históricas de possibilidade de emergência desse espaço, e da relaçáo desse espaço com o próprio campo científico e os demais campos. Assim, seus achados precisam ser ampliados para testar com robustez a hipótese levantada. Por fim, aponta-se a necessidade de estudos futuros que possam analisar as transformaçôes nesse espaço emergente e apontar as disputas que consolidarão um ponto de vista dominante sobre a classificação e as questóes centrais de saúde desse grupo. ${ }^{1}$

\section{Referências}

ALBUQUERQUE, G. A. et al. Access to health services by lesbian, gay, bisexual, and transgender persons: systematic literature review. BMC Int Health Hum Rights, v. 16, n. 2, p. 1-10, 2016.

ALMEIDA, G.; MURTA, D. Reflexóes sobre a possibilidade da despatologização da transexualidade e a necessidade da assistência integral à saúde de transexuais no Brasil. Sex., Salud Soc., Rio de Janeiro, n. 14, p. 380-407, 2013.

AQUINO, E. M. et al. Gênero, sexualidade e saúde reprodutiva: a constituiçấo de um novo campo na Saúde Coletiva. Cad Saúde Pública. Rio de Janeiro, v. 19, supl 2, p. 198-199, 2003.

AQUINO, E. M. Gênero e saúde: perfil e tendências da produção científica no Brasil. Rev. Saude Publica. São Paulo, v. 40, p. 121-132, 2006.

ARÁN, M.; MURTA, D.; LIONÇO, T. Transexualidade e saúde pública no Brasil. Ciênc. saúde coletiva. Rio de Janeiro, v.14, n.4, p. 1141-1149, 2009.

ARÁN, M.; ZAIDHAFT, S.; MURTA, D. Transexualidade: corpo, subjetividade e saúde coletiva. Psicol. Soc. Belo Horizonte, v. 20, n. 1, p. 70-79, 2008. 
ARAUJO, L. M.; PENNA, L. H. G. A relação entre sexo, identidades sexual e de gênero no campo da saúde da mulher. Rev enferm UERJ. Rio de Janeiro, v. 22, n. 1, p. 134-138, 2014.

ASSIS, S. G.; GOMES, R.; PIRES, T. O. Adolescência, comportamento sexual e fatores de risco à saúde. Rev. Saúde Pública. São Paulo, v. 48, n. 1, p. 43-51, 2014.

ATHAYDE, A. V. L. Transexualismo masculino. Arq Bras Endocrinol Metab., São Paulo, v. 45, n. 4, p. 407-414, 2001.

BARBOSA, R. M.; FACCHINI, R. Acesso a cuidados relativos à saúde sexual entre mulheres que fazem sexo com mulheres em São Paulo, Brasil. Cad. Saúde Pública [online], v. 25, supl. 2, p. 291-300, 2009. Disponível em: <http://dx.doi.org/10.1590/S0102-311X2009001400011>. Acesso em: 27 mar. 2018.

BARRIENTOS, J. et al. Medidas de salud mental y bienestar subjetivo en una muestra de hombres gays y mujeres lesbianas en Chile. Rev. méd. Chile. Santiago, v. 145, n. 9, p. 1115-1121, 2017.

BARROS, S. G.; VIEIRA-DA-SILVA, L. M. A gênese da política de luta contra a Aids e o Espaço Aids no Brasil (1981-1989). Rev Saúde Pública. São Paulo, v. 50, p. 1-12, 2016.

BENTO, B. A reinvenção do corpo: sexualidade e gênero na experiência transexual. Rio de Janeiro: Garamond, 2006.

. Transviados: gênero, sexualidade e direitos humanos. Salvador: EDUFBA, 2017.

BERTOLIN, D.C. et al. Conhecimento de mulheres que fazem sexo com mulheres sobre o Papilomavírus Humano. Cogitare Enferm., Curitiba, v.15, n.4, p.730-735, 2010.

BLOSNICH, J.; LEE, J.G.; HORN, K. A systematic review of the aetiology of tobacco disparities for sexual minorities. Tob Control, v.22, n.2, p. 66-73, 2013.

BOURDIEU, P. A distinção: crítica social do julgamento. Porto Alegre: Zouk, 2008.

. A dominação masculina. A condição feminina e a violência simbólica. Rio de Janeiro:

Bestbolso, 2014a.

. Os usos sociais da ciência: por uma sociologia clínica do campo científico. São Paulo:

UNESP; 2004.

. Razóes práticas. Sobre a teoria da ação. 11ª ed, Campinas: Papirus Editora, 2011.

. Sobre o Estado: Cursos no Collège de France (1989-92). São Paulo: Companhia das

Letras, 2014b.

CARRARA, S. Políticas e direitos sexuais no Brasil contemporâneo. BAGOAS, Natal, v.4, n. 5, p. 131-147, 2010.

CARVALHO, D. S. O gênero e a ciência da saúde: produção em torno da transexualidade no Portal de pesquisa da Biblioteca Virtual de Saúde. Dissertação (Mestrado Acadêmico em Saúde, Ciclos de Vida e Sociedade) - Universidade de São Paulo, São Paulo: 2014. 
CARVALHO, M.; CARRARA, S. Em direção a um futuro trans? Contribuição para a história do movimento de travestis e transexuais no Brasil. Sex., Salud Soc. (Rio J.) [online], n. 14, p. 319-351, 2013. Disponível em: <http://dx.doi.org/10.1590/S1984-64872013000200015 >. Acesso em: 27 mar. 2018.

COSTA, E. M. F.; MENDONÇAA, B. B. Manejo clínico de sujeitos transexuais. Arq Bras Endocrinol Metab., São Paulo, v. 58, n. 2, p. 188-196, 2014.

CUNHA, R. B. B.; GOMES, R. Os jovens homossexuais masculinos e sua saúde: uma revisão sistemática. Interface, Botucatu, v. 19, n. 52, p. 57-70, 2015.

FACCHINI, R.; DANILIAUSKAS, M.; PILON, A. C. Políticas sexuais e produção de conhecimento no Brasil: situando estudos sobre sexualidade e suas conexóes. Revista de Ciências Sociais, Fortaleza, v. 44, n. 1, p. 161-193, 2013.

FERNANDES, B. Educação popular em saúde: um diálogo da sociedade civil com os postos de saúde em Goiânia. Tempus, actas de saúde colet. Brasília, v. 11, n. 1, p. 15-41, 2017.

FRANCO, T. et al. Transgenitalização masculino / feminino: experiência do Hospital Universitário da UFRJ. Rev. Col. Bras. Cir., Rio de Janeiro, v. 37, n. 6, p. 426-434, 2010.

FREDRIKSEN-GOLDSEN, K.I.; MURACO, A. Aging and Sexual Orientation: A 25-Year Review of the Literature. Res Aging, v. 32, n. 3, p. 372-413, 2010.

GIAMI, A. Sexuality, health and human rights: The invention of sexual rights. Sexologies, v. 24, n. 3, p. 45-33, 2015.

GOMES, R. et al. Gênero, direitos sexuais e suas implicaçôes na saúde. Ciênc. saúde coletiva [online], v. 23, n. 6, p. 1997-2006, 2018. Disponível em: <http://dx.doi.org/10.1590/141381232018236.04872018>. Acesso em: 10 ago. 2018.

GONZALEZ, E. et al. Orientación sexual: un desafío actual para la atención de adolescentes. Rev. Soc. Chil. Obstet. Ginecol. Infant. Adolesc, Santiago, v. 11, n. 3, p. 69-78, 2004.

HENDERSON, H. J. Why lesbians should be encouraged to have regular cervical screening. J Fam Plann Reprod Health Care, v. 35, n. 1, p. 49-52, 2009.

LIONÇO, T. Atenção integral à saúde e diversidade sexual no Processo Transexualizador do SUS: avanços, impasses, desafios. Physis. Rio de Janeiro, v. 19, n. 1, p. 43-63, 2009.

LOZANO-VERDUZCO, I.; FERNÁNDEZ-NIÑO, J. A.; BARUCH-DOMÍNGUEZ, R. Association between internalized homophobia and mental health indicators in LGBT individuals in Mexico City. Salud Mental, México, v. 40, n. 5, p. 219-225, 2015.

MAHER, M. J. et al. Hirschfeld to hooker to herek to high schools: a study of the history and development of GLBT empirical research, institutional policies, and the relationship between the two. J Homosex., v. 56, n. 7, p. 921-958, 2009. 
MARSHAL, M. P. et al. Suicidality and Depression Disparities Between Sexual Minority and Heterosexual Youth: A Meta-Analytic Review. J Adolesc Health, v. 49, n. 2, p. 115-23, 2011.

MELLO, L. et al. Políticas de saúde para lésbicas, gays, bissexuais, travestis e transexuais no Brasil: em busca de universalidade, integralidade e equidade. Sex., Salud Soc. Rio de Janeiro, n. 9, p. 7-28, 2011.

MONTOYA, J. H. E.; SÁNCHEZ-ALFARO, L. A. Las violencias de género como problema de salud pública: una lectura en clave Bioética. Revista Colombiana de Bioética, v. 6, n. 1, p. 37-61, 2011.

MORA, C.; BRIGEIRO, M.; MONTEIRO, S. A testagem do HIV entre "HSH": tecnologias de prevenção, moralidade sexual e autovigilância sorológica. Physis, Rio de Janeiro, v. 28, n. 2, p. 1-28, 2018.

MORRISON, M. A. et al. Systematic review of the psychometric properties of transphobia scales. International Journal of Transgenderism, v. 18, n. 4, p. 395-410, 2017.

NATARELLI, T. R. P. et al. O impacto da homofobia na saúde do adolescente. Esc. Anna Nery, Rio de Janeiro, v.19, n.4, p. 664-670, 2015.

ORTIZ-HERNÁNDEZ, L.; GRANADOS, J. A. C. Violencia hacia bisexuales, lesbianas y homosexuales de la Ciudad de México. Rev. Mex. Sociol., v. 65, n. 2, p. 265-303, 2003.

ORTIZ-HERNÁNDEZ, L.; TORRES, M. I. G. Efectos de la violencia y la discriminación en la salud mental de bisexuales, lesbianas y homosexuales de la Ciudad de México. Cad. Saúde Pública, Rio de Janeiro, v. 21, n. 3, p. 913-925, 2005.

PEREIRA, E. O. et al. Unidades básicas de saúde em Teresina-PI e o acesso da população LGBT: o que pensam os médicos? Tempus, actas de saúde colet. Brasília, v. 11, n. 1, p. 51-67, 2017.

PERUCCHI, J.; BRANDÃO, B. C.; VIEIRA, H. I. S. Aspectos psicossociais da homofobia intrafamiliar e saúde de jovens lésbicas e gays. Estud. psicol. Natal, v. 19, n. 1, p. 67-76, 2014.

PRADO, E. A. J.; SOUSA, M. F. Políticas públicas e a saúde da população LGBT: uma revisão integrativa. Tempus, actas de saúde colet., Brasília, v. 11, n. 1, p. 69-80, 2017.

RAIMONDI, G. A.; PAUlinO, D. B.; TEIXEIRA, F. B. O que importa? As Pesquisas Brasileiras no Campo da Saúde e as (In)visibilidades das Travestis e Transexuais. Sau. \& Transf. Soc, Florianópolis, v. 7, n. 3, p. 133-146, 2016.

RINALDI, D. O corpo estranho. Rev. Latinoam. Psicopat. Fund. São Paulo, v. 14, n. 3, p. $440-$ 451, 2011.

ROBINSON, K. et al. Lesbian and bisexual women's gynaecological conditions: a systematic review and exploratory meta-analysis. BJOG, v. 124, n. 3, p. 381-392, 2017.

RODRÍGUEZ, L. M. I. Trastornos de la identidad de género en la niñez. Perinatol Reprod Hum, México, v. 15, n. 1, p. 52-59, 2001. 
SIBERMAN, P.; BUEDO, P.E.; BURGOS, L. M. Barreras en la atención de la salud sexual en Argentina: percepción de las mujeres que tienen sexo con mujeres. Rev. salud pública, v. 18, n. 1, p. 1-12, 2016.

SILVA, F. R.; NARDI, H. C. A construção social e política pela não-discriminação por orientação sexual. Physis [online], v. 21, n. 1, p. 251-265, 2011. Disponível em: <http://dx.doi. org/10.1590/S0103-73312011000100015>. Acesso em: 18 dez. 2017.

SIMÓES, J. A.; CARRARA, S. O campo de estudos socioantropológicos sobre diversidade sexual e de gênero no Brasil: ensaio sobre sujeitos, temas e abordagens. Cad. Pagu [online], n. 42, p. 75-98, 2014. Disponível em: < http://dx.doi.org/10.1590/0104-8333201400420075>. Acesso em: 02 de set. 2017.

SPIZZIRRII, G. Transexualismo e neuroimagem. Diagn Tratamento, São Paulo, v.17, n.1, p.3235, 2012.

TEIXEIRA-FILHO, F. S.; RONDINI, C. A. Ideaçóes e tentativas de suicídio em adolescentes com práticas sexuais hetero e homoeróticas. Saude soc., São Paulo, v. 21, n. 3, p. 651-667, 2012. TOMICIC, A. et al. Suicidio en poblaciones lesbiana, gay, bisexual y trans: revisión sistemática de una década de investigación (2004-2014). Rev. méd. Chile. Santiago, v. 144, n. 6, p. 723-733, 2016.

VET, R.; WIT, J. B.; DAS, E. Factors associated with hepatitis B vaccination among men who have sex with men: a systematic review of published research. Int J STD AIDS, v. 28, n. 6, p. 534-542, 2017.

VILLELA, W.; MONTEIRO, S.; VARGAS, E. A incorporação de novos temas e saberes nos estudos em saúde coletiva: o caso do uso da categoria gênero. Ciênc. saúde coletiva [online], v. 14, n.4, p.997-1006, 2009. Disponível em: <http://dx.doi.org/10.1590/S141381232009000400002>. Acesso em: 20 mar. 2018.

\section{Nota}

${ }^{1}$ E. A. F. Abade: concepção, planejamento, análise e interpretação de dados, redação e revisão crítica do manuscrito. S. Chaves e G. Silva: análise e interpretação de dados, redação e revisão crítica do manuscrito. 


\section{Abstract}

Health of the LGBT population: an analysis of agents, objects of interest and disputes in an emerging scientific production space

Systematic review of scientific production on the health of lesbians, gays, bisexuals, transvestites and transsexuals (LGBT) in Latin America from 2001 to 2018. We analyzed 161 articles indexed on the bases of SciELO, LILACS, Pubmed and Web of Science. The analysis was based on the concepts of field, agents and capital of Pierre Bourdieu and revealed that there is an emerging space of production on the theme, occupied mainly by agents of Public Health, Psychology, Nursing and Psychiatry. In this space, the issue of violence and discrimination and its effects on mental health, education and professional performance has been the main object of interest, along with the repercussions of body changes for transvestites and transsexuals. It is noteworthy that the subgroups, lesbians, gays, bisexuals, transvestites and transsexuals are targets of different research objects, the central dispute of categorization by science of each of these groups remaining.

> Keywords: LGBT; homosexuality; bisexuality; transgender persons; health. 